Ömeroğlu, A. F. ve Onan, B. (2021). Türkçe Dil Bilgisi Tutum Ölçeğinin (TDTÖ) geliştirilmesi: Geçerlik ve güvenirlik çalışması. Ana Dili Eğitimi Dergisi, 9(3), 978-992.

Ana Dili Eğitimi Dergisi
Journal of Mother Tongue Education
www.anadiliegitimi.com
Geliş/Received: 01.06.2021 Kabul/Accepted: 08.07 .2021
Araştırma Makalesi / Research Paper

\title{
Türkçe Dil Bilgisi Tutum Ölçeğinin (TDTÖ) Geliştirilmesi: Geçerlik ve Güvenirlik Çalışması*
}

\author{
Ali Ferhat ÖMEROĞLU** \\ Bilginer ONAN***
}

\begin{abstract}
Öz
Bu araştırmada, ortaokul öğrencilerinin Türkçe dil bilgisine yönelik tutumlarını ölçecek nitelikte bir tutum ölçeğinin geliştirilmesi amaçlanmıştır. Araştırmanın çalışma grubu; açımlayıcı faktör analizi için 574, doğrulayıcı faktör analizi için 342 ortaokul öğrencisinden oluşmaktadır. Ölçeğin taslak formunda yer alan 41 maddenin ortaokul öğrencilerine uygulanmasından sonra açımlayıcı faktör analizi (AFA) yapılmıştır. Bu analiz ve uzman görüşüyle birlikte araçtan 18 madde atılarak toplam varyansın \%58,96'sını açıklayan üç faktörlü bir form elde edilmiştir. Üç faktörlü yapının model uyumunu sınamak için doğrulayıcı faktör analizi (DFA) yapılmış ve elde edilen sonuçlar $\left(\chi^{2} / \mathrm{sd}=2,21 ; \mathrm{RMSEA}=.06 ; \mathrm{CFI}=.98 ; \mathrm{NNFI}=.98 ; \mathrm{NFI}=.97 ; \mathrm{GFI}=.89 ; \mathrm{SRMR}=.05\right)$ modelin uyum indekslerinin iyi düzeyde olduğunu göstermiştir. Araştırmada dil bilgisiyle ilgili yazılan maddelerden hareketle tespit edilen boyutlar; "Sevgi ve Ilgi", "Gereklilik" ve "Kaygı" olarak adlandırılmıştır. Bu yönüyle Likert tipi ölçek hazır hâle getirilmiştir. Ölçeğin güvenirlik hesaplamalarında Cronbach Alpha güvenirlik katsayısı .93 olarak bulunmuştur. Aynı zamanda ölçeğin toplam maddeleri ile faktörlere ait maddeler arasındaki ilişkiyi belirlemek için Pearson Korelasyon Katsayıları hesaplanmıştır. Bu analizler sonucunda elde edilen bulgular, 23 maddeden oluşan Türkçe Dil Bilgisi Tutum Ölçeğinin (TDTÖ) geçerli ve güvenilir bir ölçme aracı olduğunu göstermiştir.
\end{abstract}

Anahtar Kelimeler: Dil bilgisi, tutum ölçeği, geçerlik, güvenirlik

\section{Developing Attitudes Scale Towards Turkish Grammar (ASTG): A Validity and Reliability Study}

\begin{abstract}
This study aims to develop an attitudes scale to measure the attitudes of secondary school students towards Turkish grammar. The study group consists of a total of 574 secondary school students for the exploratory factor analysis and 342 secondary school students for the confirmatory factor analysis. Prior to the conduct of the exploratory factor analysis (EFA), 41 items in the draft scale were administered to the students. After this analysis, 18 items were exlcluded from the measurement tool based on expert opinion; the resulting tool consists of three factors explaining $58.96 \%$ of the total variance. Confirmatory factor analysis (CFA) was performed to test the model fit of the three-factor structure; the findings $\left(\chi^{2} / s d=2,21 ; \operatorname{RMSEA}=\right.$ $.06 ; \mathrm{CFI}=.98 ; \mathrm{NNFI}=.98 ; \mathrm{NFI}=.97 ; \mathrm{GFI}=.89 ; \mathrm{SRMR}=.05)$ showed that the fit indices of the model are acceptable. This study identified the following dimensions based on the items related to grammar: "Liking and Interest", "Necessity" and "Anxiety." The Likert-type scale was finalized accordingly. The Cronbach's Alpha reliability coefficient of the scale was found as .93. Also,

\footnotetext{
${ }^{*}$ Bu çalışma, birinci yazarın ikinci yazar danışmanlığında hazırladığı doktora tezinden üretilmiştir.

** Arş. Gör. Dr., Hatay Mustafa Kemal Üniversitesi, Eğitim Fakültesi, Türkçe Eğitimi Bölümü, Hatay, ferhat.omeroglu@hotmail.com, ORCID: orcid.org/0000-0002-1756-7041

${ }^{* * *}$ Prof. Dr., Hatay Mustafa Kemal Üniversitesi, Eğitim Fakültesi, Türkçe Eğitimi Bölümü, Hatay, bilgineronan@gmail.com, ORCID: orcid.org/0000-0002-1051-5329
} 
Pearson Correlation Coefficients were calculated to determine the correlation between the total items of the scale and the items under the factors. The results proved that the Attitudes Scale towards Turkish Grammar (ASTG) is a valid and reliable measurement tool.

Key Words: Grammar, attitudes scale, validity, reliability

\section{Giriş}

Insanlar, bir anlaşma aracı olarak kullandıkları dil sayesinde duygularını ve düşüncelerini ifade ederler. Uzlaşıma dayalı olarak geliştirilmiş olan dil, kendisine özgü kurallardan oluşur. Bu kuralları ayrıntısıyla inceleyen bilime ise dil bilgisi adı verilir. Bir dilde anlama ve anlatma becerilerinin doğru bir şekilde kullanılabilmesi için o dilin dil bilgisine hâkimiyet önemlidir. Öğretim programına göre hazırlanmış bir dil bilgisi öğretimiyle bireylerin dil becerilerini geliştiren etkinliklere yer verilebilir. Dil becerilerinin geliştirilmesinde yardımcı ve destekleyici bir alan olan dil bilgisi öğretiminin en önemli amacı, öğrencilerin ana dillerini kusursuz bir biçimde öğrenmeleridir (Dolunay, 2010; Aytaş ve Çeçen, 2010). Bu alanla ilgili çalışmalara başlamadan önce öğrencilerin dil bilgisine yönelik tutumlarının incelenmesi, öğretim ortamında yapılması planlanan çalışmalara zemin hazırlar. Çünkü tutumlar bireyin dünyasında yer alan bazı sembol, nesne veya görüşleri olumlu veya olumsuz bir şekilde değerlendirme eğilimidir (Katz, 1960, s. 168). Doğuştan gelmeyip yaşantılar yoluyla öğrenilirler; geçici olmayıp belirli bir süre devamlılık gösterirler. Olumlu veya olumsuz bir tutumun oluşması, karşılaştırmalar sonucunda mümkün olup kişisel ve toplumsal tutumlardan bahsedilebilir (Tavşancıl, 2006, s. 71-72). Bu yönüyle bireylerin davranışlarını yönlendirici bir etkiye sahiptirler. Özkaya ve Coşkun $(2018$, s. 638)'a göre “öğrencilerin dil bilgisine yönelik tutumlarının belirlenmesi, eğitim öğretim sürecindeki eksikliklerin giderilmesine ve öğretim programının öğrencilerin ilgi ve başarılarını artıracak şekilde düzenlenmesine olanak sağlayacaktır." Aynı zamanda öğretmen tarafından tasarlanan uygulamaların tutum üzerindeki etkilerini görebilmek amacıyla da öğrencilerin dil bilgisine yönelik tutumlarını incelemek mümkündür. Bu amaçlar doğrultusunda ortaokul öğrencilerinin Türkçe dil bilgisine yönelik tutumlarını belirleyebilmek için geliştirilen tutum ölçeği; "Sevgi ve Illgi", "Gereklilik" ve "Kaygı" olmak üzere üç boyutta ele alınmıştır.

Sevgi ve Illgi boyutu; öğrencilerin dil bilgisi öğrenirken sevme, eğlenme, merak duyma, istekli olma gibi davranışlarına yönelik tutumları içermektedir. Bu tutumların olumlu veya olumsuz bir davranış olarak gerçekleşmesi, dil bilgisinin öğretim şekliyle bağlantılıdır. Türkçe derslerinde dil bilgisi kurallarının ezberletilerek öğretilmesi, öğrencilerin dil bilgisine karşı olumsuz tutum sergilemelerine sebep olabilmektedir. Nitekim dil bilgisi kurallarının ezberletilmesi yerine bu kuralların sezdirilerek öğrencide birer beceri ve alışkanlık oluşturmasına yönelik görüşler mevcuttur (Göğüş, 1978; Erdem ve Çelik, 2011; Güven, 2013; Güneş, 2013). Dil bilgisi kurallarının öğrencilerin günlük hayatlarındaki intiyaçlarını karşılayacak şekilde öğretilmesine dikkat edilmelidir. İşcan ve Kolukısa (2005, s. 300), ezberletilerek öğretilen dil bilgisinin öğrenciler tarafından sevilmediğini belirtmektedir. Aynı şekilde Salman ve Aydın da (2018, s. 1280), ezberci anlayışla öğretilmeye çalışılan dil bilgisinin öğrenciler tarafından kullanılamadığını ve bu durumun öğrencilerde dil bilgisine karşı olumsuz tutum edinmelerine neden olduklarını dile getirmektedirler. Oysa dil bilgisi öğretimi, öğrencilerde bir dil farkındalığı ve dil bilinci oluşturmak amacıyla gerçekleştirilmelidir.

Gereklilik boyutu; öğrencilerin dil bilgisi öğrenmeye ihtiyaç duyup duymadıklarına yönelik tutumları içermektedir. Dil bilgisi öğretiminin gerekli olup olmadığı konusunda farklı görüşler mevcuttur. Tompkins (1998, s. 511), dil bilgisini dil sanatının en tartışmalı alanı olarak görmüş ve bu alanın hangi içerikle, nasıl ve ne zaman öğretilmesiyle ilgili uzlaşıma varılamadığını belirtmiştir. Dil bilgisinin dil öğretimi alanında sıklıkla yanlış anlaşıldığını dile getiren Larsen-Freeman $(1997$, s. 1) ise yapıların öğretilmemesi gerektiği ve kendiliğinden kazanılacağına yönelik yanlış düşüncelerin olduğunu belirtmiştir. Bu düşüncelere karşı Larsen-Freeman (1997, s. 1) ve Zhang (2009, s. 184-186), dil bilgisinin keyfí kurallardan oluşmadığı, sıkıcı olmadığı ve öğretilmesinin gerekli olduğu görüşlerini savunmuşlardır. Göğüş ise (1978, s. 339), ülkemizde de dil bilgisi öğretimine yönelik tartışmaların olduğunu ifade etmiştir. Bu tartışmalar, bugün de devam etmekte olup dil bilgisi öğretiminin Türkçe Dersi Öğretim Programlarına yansıtılma durumlarında değişikliklerle karşılaşılmaktadır. Oysa dil bilgisi konularının hangi amaçla öğretildiğinin öğrenciler tarafından anlaşılması gerekir. Onan (2017, s. 2632), 
dil bilgisi öğretiminde sentezci bir yaklaşım önererek bu yaklaşımı ontolojik farkındalık oluşturma, konu anlatımı, kavrama/kavratma ve pragmatik olmak üzere dört aşamada sınıflandırmış olup dil bilgisinin neden öğretilmesi gerektiğine öncelikle ontolojik farkındalık aşamasıyla başlanması gerektiğini belirtir. Bu aşamada dil bilgisi konusunun dildeki işlev ve intiyaç boyutu vurgulanmaktadır. Nitekim Hamzadayı ve Şentürk de (2020, s. 100), dil bilgisi öğretim sürecinin öğrenci gereksinimleri, deneyimler ve günlük hayattaki kullanımları dikkate alınarak işlevsel bir şekilde tasarlanması gerektiğini ifade etmektedirler.

Kaygı boyutu; öğrencilerin dil bilgisi konularını öğrenmeyi kolay veya zor bulması, dil bilgisi sorularında başarılı olup olmama gibi düşüncelerine yönelik tutumları içermektedir. Sınıf düzeylerine göre belirlenmiş dil bilgisi konularının birbirini takip eden bir sıralılık arz ettiği bilinmektedir. Bu yönüyle değerlendirildiğinde herhangi bir konuyu öğrenmek için konular arasındaki bağlantılar iyi kurulmalıdır. Örneğin, sıfat konusunun anlaşılması için isim konusunu bilmek ya da cümleyi ögelerine ayırabilmek için öncesinde sözcük gruplarını öğrenmek gerekir. Dil bilgisi konularının birbirleriyle bağlantılı olması nedeniyle önceliğe sahip bir konuyu iyi öğrenemeyen öğrenciler, bir sonraki konuyu öğrenirken zorluk yaşayabilir. Bununla birlikte öğrencilerin dil bilgisi sorularına yönelik deneyimlerinin kaygıyı ortaya çıkarabileceği muhtemeldir. Genellikle dil bilgisi terimlerinin yer aldığı bu tür sorularda, ilgili terim hakkında herhangi bir bilgiye sahip olmayan öğrencilerin sorulara yönelik tutumlarının değerlendirilmesi gerekir. Özellikle belirli ve aynı kavramı karşılayan, ancak farklı adlandırılan terimlerle karşılaşılması, dil bilgisine yönelik tutumları etkileyici nitelikte olabilir. Kurudayıoğlu $(2014$, s. 57) da dil bilgisi öğretiminin sorunları içerisinde terimlere karşılık bulma konusunda yapılan hataları düzeltmek için çaba harcanmasına rağmen kesin bir çözüme ulaşılamadığını belirtmektedir. Bu açıdan bakıldığında öğretilmesi amaçlanan dil bilgisi terimlerinin ders kitaplarında ortak kullanımına özen gösterilmelidir. Dil bilgisine yönelik tutumların belirlenmesinde bu üç boyuta dikkat edilerek öğretim programı, Türkçe ders kitapları ve sınıf ortamına yönelik düzenlemelerin yapılması önemlidir. Literatürde dil bilgisine yönelik geliştirilen az sayıda tutum ölçeği ile karşılaşılmışır (Er ve Topçuoğlu Ünal, 2016; Özkaya ve Coşkun, 2018). Bu nedenle söz konusu çalışmada ortaokul öğrencilerinin Türkçe dil bilgisine yönelik tutumlarını belirleyebilecek nitelikte bir ölçme aracının geliştirilmesi amaçlanmıştır.

\section{Yöntem}

Bu çalışma, Türkçe Dil Bilgisi Tutum Ölçeğinin geçerliğini ve güvenirliğini belirlemeye yönelik hazırlanan ölçekleme temelli bir araştırmadır.

\section{Çalışma Grubu}

Araştırmanın açımlayıcı faktör analizi ve doğrulayıcı faktör analizine ait çalışma grubu; 20182019 eğitim-öğretim dönemi bahar yarıyılında Hatay ì Millî Eğitim Müdürlüğünden alınan izin doğrultusunda Hatay ili Merkez ilçesindeki devlet ortaokullarııın 5, 6, 7 ve 8. sınıflarında öğrenim gören ve rastlantısal olarak seçilen öğrencilerden oluşmaktadır. Faktör analizinin yapılabilmesi için seçilen örneklem büyüklüğü; ölçek formunda yer alan madde sayısının en az 5 katı, hatta 10 katı kadar olması gerekmekte; 300 ve üzerindeki sayıların iyi bir örneklem büyüklüğü olduğu düşünülmektedir (Tavşancıl, 2006; Tabachnick \& Fidell, 2013). Toplanan 703 formun 129'u; maddeler üzerinde boş bırakma, sistematik işaretlemeler yapma, rastgele doldurma nedenleriyle devre dışı bırakılmıştır. Açımlayıcı faktör analizi (AFA); 5. sınıflarda 148, 6. sınıflarda 133, 7. sınıflarda 150 ve 8. sınıflarda 143 olmak üzere toplam 574 öğrenci üzerinde gerçekleştirilmiştir. Aynı zamanda 292 öğrencinin kız, 282 öğrencinin erkek olduğu tespit edilmiş olup bu öğrencilerin 41 maddeye verdiği cevaplar derecelerin toplamıyla hesaplanmıştır. Doğrulayıcı faktör analizi (DFA); 5. sınıflarda 88, 6. sınıflarda 90, 7. sınıflarda 94 ve 8. sınıflarda 70 olmak üzere toplam 342 öğrenci üzerinde gerçekleştirilmiştir. Analizde 179 öğrencinin kız, 163 öğrencinin erkek olduğu tespit edilmiş olup bu öğrencilerin 23 maddeye verdiği cevaplar derecelerin toplamıyla hesaplanmıştır.

\section{Ölçme Aracının Geliştirilmesi \\ Madde Havuzu Oluşturma}

Ortaokul 5, 6, 7 ve 8. sınıflarda uygulanması için geliştirilen Türkçe Dil Bilgisi Tutum Ölçeğine (TDTÖ) yönelik literatür taraması yapılmış ve Türkçe eğitimi alanında geliştirilmiş tutum ölçeklerinin 
maddeleri incelenmiştir (Acat, 2000; Gömleksiz, 2003; MEB, 2006; Kuşdemir Kayıran, 2007; Özbay ve Uyar, 2009; İşeri ve Ünal, 2010; Topçuoğlu Ünal ve Köse, 2014; Çerçi ve Derman, 2016; Er ve Topçuoğlu Ünal, 2016; Özkaya ve Coşkun, 2018). Maddelerin bilişsel, duyuşsal ve davranışsal ifadeleri kapsamasına; olumlu ve olumsuz ifadelerin gözlenebilir ve ölçülebilir özellikleri içermesine dikkat edilmiştir. Bu ölçütler dikkate alınarak madde havuzunda yer alan 48 madde uzman görüşleri doğrultusunda değerlendirilmiş ve sonuç olarak 41 adet madde, ölçeğin taslak formunda uygulamaya hazır hâle getirilmiştir. Beşli likert tipinde geliştirilen ölçekte "Tamamen Katılıyorum", "Katılıyorum", "Kararsızım", "Katılmıyorum" ve "Kesinlikle Katılmıyorum" seçeneklerine yer verilmiştir. Likert ölçekleme modeli, daha çok sezgilere dayanmakta; ölçekte seçeneklere yönelik verilen puanlar toplanarak sonuçlar elde edilmektedir (Tezbaşaran, 2008, s. 5).

\section{Uzman Görüşüne Başvurma}

TDTÖ’nün geliştirilmesi için oluşturulan taslak formda dil bilgisi konu alanını içeren toplam 48 madde hazırlanmıştır. Sonrasında bu maddeler; içerik, anlatım ve yazımla ilgili ölçütleri kontrol edebilmek amacıyla Türkçe eğitimi alanında çalışan 4 öğretim üyesi, ölçme ve değerlendirme alanıyla psikolojik danışmanlık ve rehberlik alanında çalışan 2 öğretim üyesinin görüşleri doğrultusunda incelenmiştir. Uzmanların görüşleri doğrultusunda yazılan maddelerde düzeltmeler gerçekleştirilmiş, ölçeğin ölçütleri dikkate alınarak 7 maddenin formdan çıkarılması uygun görülmüştür. Dil bilgisiyle ilgili ölçeğin son taslak formunda 41 maddeye yer verilmiş olup bu maddelerin 20'sinin olumlu, 21'inin olumsuz ifadeleri içerdiği belirlenmiştir. Tutumla ilgili maddelerin ölçek formuna yerleştirilmesinde rastgele bir sıralama gerçekleştirilerek bireylerin aynı boyutları içeren maddelere verecekleri yanıtlarda etkilenmemesine dikkat edilmiştir. Maddeler hazırlandıktan sonra araştırmacı tarafından ölçek formunun yanıtlanmasını kolaylaştıracak işlemlerle ilgili bir yönerge hazırlanmıştır.

\section{Pilot Uygulama}

Ölçek formunda yer alan maddelerin ortaokul öğrencileri tarafından anlaşııı anlaşılmadığını kontrol etmek amacıyla her sınıf düzeyinden iki öğrenciyle görüşme gerçekleştirilmiştir. Maddelerin öğrenciler arasında farklı anlaşılmalara sebebiyet vermemesine dikkat edilerek öğrenciler tarafından farklı anlaşılan maddelerle uzman görüşlerinde çıkarılması uygun görülen maddelerin birbirleriyle benzerlik taşıdığı anlaşılmıştır. Buna bağlı olarak 41 maddeden oluşan ölçek formu, uygulamaya hazır hâle getirilmiştir.

\section{Verilerin Analizi}

\section{Yapı Geçerliği (Faktör Analizi)}

Yapı geçerliği, bireyin psikolojik özelliklerini ölçmek amacıyla hazırlanan soruların belirtilen özellikleri doğru bir şekilde ölçebilme derecesidir (Büyüköztürk, 2017, s. 180). Ölçeğin yapı geçerliğini sağlayabilmek amacıyla faktör analizi yapılmıştır. Faktör analizi, birbiriyle ilişkili çok sayıda değişkenin sayısını azaltmak, değişkenler arasındaki ilişkilerde yapıyı ortaya çıkarmak, değişkenleri sınıflandırmak amacıyla kullanılan istatistik tekniğidir (Kalaycı, 2018, s. 321). Bu amaç doğrultusunda hazırlanan ölçeğin taslak formu, ortaokul öğrencilerine uygulanarak açımlayıcı ve doğrulayıcı faktör analizi gerçekleştirilmiştir.

\section{Açımlayıcı Faktör Analizi}

Araştırmada ölçeğin değişkenlere bağlı olarak hangi boyutları içerdiğini tespit edebilmek amaçlanmıştır. Pallant (2007, s. 179)'a göre açımlayıcı faktör analizi, ilk aşamada bir dizi değişken arasındaki ilişki hakkında bilgi toplamak (keşfetmek) amacıyla kullanılmaktadır. Likert tipinde hazırlanan 41 maddelik taslak form, 574 öğrenciye uygulanmış ve öğrencilerden alınan cevaplar, derecelerin toplamıyla hesaplanmıştır. Olumsuz maddelerin 1, 2, 3, 4, 5 puana dönüştürülmesinde SPSS'nin aynı değişkeni yeniden kodlama adlı seçeneği kullanılmıştır. Leech, Barrett ve Morgan (2005, s. 28), skewness ve kurtosis değerlerinin -1 ile +1 arasında olmasının normalliği karşıladığını belirtmekte olup faktör analizinin yapılabilmesi için toplanan veriler üzerinde skewness $(-, 523)$ ve kurtosis $(-, 538)$ değerleri incelenerek bu değerlerin normalliği karşıladığı görülmüştür. 


\section{Doğrulayıcı Faktör Analizi}

Araştırmanın bu aşamasında açımlayıcı faktör analizi sonucu değişkenler arası ilişkiden hareketle keşfedilen boyutların farklı çalışma gruplarına uygulandığında doğrulanıp doğrulanmadığını kontrol etmek amacıyla doğrulayıcı faktör analizi yapılmıştır. Jöroskog ve Sörbom (1993, s. 22), bu analizin önceki çalışmalardaki bilgilerden hareketle gerçekleştirilerek bilgileri sınamak amacıyla kullanıldığını belirtmiştir. 342 öğrencinin 23 maddeye vermiş olduğu cevaplarda olumsuz maddelerin puan dönüşümleri, SPSS'nin aynı değişkeni yeniden kodlama seçeneği kullanılarak elde edilmiştir. Dönüştürülen veriler, LISREL programına aktarılarak analiz edilmiştir.

\section{Güvenirlik Hesaplama Aşaması}

Açımlayıcı ve doğrulayıcı faktör analizleri yapılarak son hâlini alan ölçeğin güvenirliğini test etmek amacıyla Cronbach Alpha iç tutarlılık katsayısı hesaplaması kullanıımıştır.

\section{Araştırma ve Yayın Etiği}

Bu çalışmada "Yükseköğretim Kurumları Bilimsel Araştırma ve Yayın Etiği Yönergesi" kapsamında uyulması belirtilen tüm kurallara uyulmuştur. Yönergenin ikinci bölümü olan "Bilimsel Araştırma ve Yayın Etiğine Aykırı Eylemler" başlığı altında belirtilen eylemlerden hiçbiri gerçekleştirilmemiştir.

\section{Yapı Geçerliğiyle ilgili Bulgular}

\section{Bulgular}

\section{Açımlayıcı Faktör Analiziyle ilgili Bulgular}

Açımlayıcı faktör analizinde çalışma grubuna katılan kişi sayısının yeterli olup olmadığını belirlemek amacıyla Kaiser-Meyer-Olkin (KMO) Testi yapılmıştır. Field (2009, s. 641)'e göre Kaiser'in ölçütü, çalışmaya katılan kişiler 250'yi aştığında ve testten elde edilen sonuçlar 0,6'ya eşit veya daha büyük olduğunda doğru olabilir. Buna bağlı olarak açımlayıcı faktör analizine ait veriler incelendiğinde KMO değeri .969 olarak bulunmuştur. Aynı zamanda korelasyon matrisindeki ilişkilerin anlamlılığını test etmek amacıyla Bartlett Küresellik Testi (Bartlett's Test of Sphericity=12839,806, df=820, $p=.000$ ) yapılarak ilgili değerin anlamlı olduğu görülmüştür. Bu sonuçlardan hareketle çalışma grubundan elde edilen verilerin açımlayıı faktör analizinin yapılmasına uygun olduğu bulunmuştur.

Açımlayıcı faktör analizinde Temel Bileşenler Analizi kullanılmıştır. Can (2017, s. 323)'a göre bu analizin kullanılmasındaki amaç, değişken sayısını azaltarak en az maddeyle en fazla bilgi toplayacak bir ölçme aracı geliştirmektir. Faktör sayılarının belirlenmesinde ise belirli ölçütlere dikkat edilmiştir. Kullanılan ölçütlerden birincisi öz değer kuralıdır. Field (2009, s. 640)' in öz değerleri 1.0 veya daha fazla olan faktörlerin korunduğu görüşüne göre faktörler belirlenmiştir.

ikinci ölçüt, çizgi grafiğine bakarak karar vermedir. Catell'in scree plot testine göre grafik üzerindeki eğrilerin yön değiştirmesi ve yatay hâle gelme durumları incelenerek faktör sayıları tespit edilebilir (Pallant, 2007, s. 182). Grafikte dikey eksen öz değer miktarını gösterirken yatay eksen faktörleri göstermekte olup yüksek ivmeli, hızlı düşüşlerin yaşandığı faktörlerin önemli faktör sayısını belirlediği bilinmektedir (Büyüköztürk, 2017, s. 135-136). Buradan hareketle TDTÖ'nün çizgi grafiği şu şekildedir: 


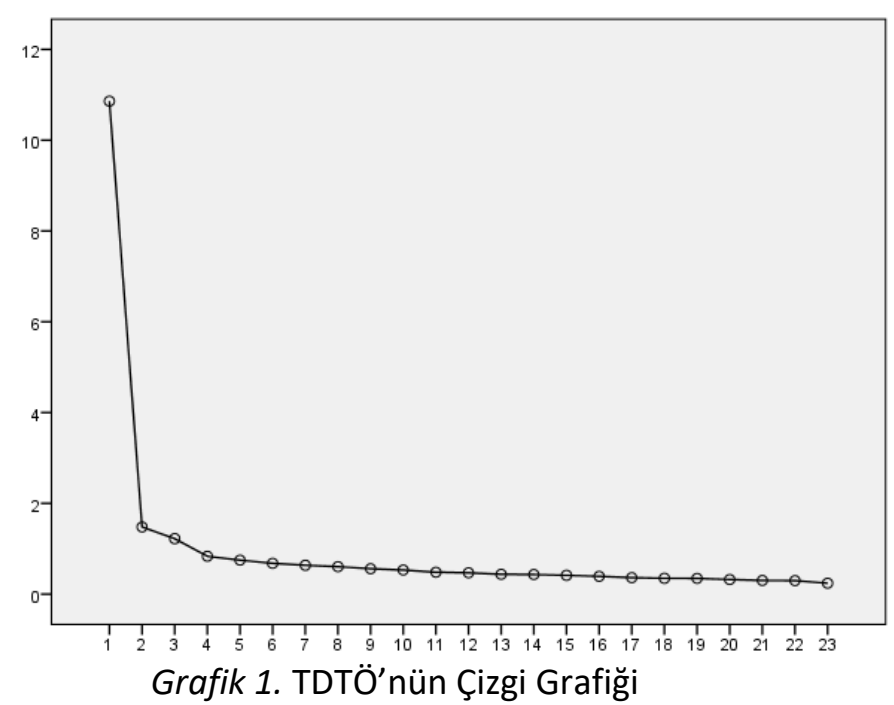

Grafik 1 incelendiğinde TDTÖ'de yer alan maddelerin sayıca birinci faktörde toplandığı görülmektedir. Çizginin yatay hâle gelme durumuna dikkat edilmiş ve TDTÖ, üç faktörlü bir yapıyla sınırlandırılarak analizler gerçekleştirilmiştir.

Üçüncü ölçüt, faktörlerin açıkladığı ek varyans yüzdelerine bakarak karar vermedir. "Faktörlerin toplam varyansın açıklanmasına getirdiği katkı \%5'in altına düştüğü anda bir önceki faktörün son faktör olduğuna ve en fazla faktör sayısına ulaşıldığına karar verilir" (Can, 2017, s. 318). Bu varyans yüzdelerine dikkat edilerek faktör sayısı belirlenmiştir.

Dördüncü ölçüt, faktör yük değerlerine göre karar vermedir. Faktör analizinde her bir değişkenin yük değerinin .32 ve daha üzerinde değerlendirilerek analiz yapılması sağlanmalıdır (Tabachnick \& Fidell, 2013, s. 654). Bu ölçüte dikkat edilmiş ve analizde .45 değeri alınarak bu değerin altında yer alan maddeler taslak formdan çıkarılmıştır.

Beşinci ölçüt, maddelerin yük değerleri arasındaki farka bakarak karar vermedir. "Bir maddenin faktörlerdeki en yüksek yük değeri ile bu değerden sonra en yüksek olan yük değeri arasındaki farkın en az .10 olmasına karar verilmiştir" (Büyüköztürk, 2017, s. 135). Buna göre yük değerleri, ilgili maddenin hangi faktörde tutulacağını belirlemek için önemlidir.

Belirlenen bu ölçütleri incelemek amacıyla Varimax döndürme yöntemi kullanılmıştır. Öncelikle döndürülmemiş faktör analizinde .45 'in altında bulunan ve yük değerleri arasındaki farka göre faktörler arasında binişiklik oluşturan taslak formdaki maddeler (t15, t23, t33, t35, t36, t37, t38, t39) ölçekten atılmıştır. Döndürme sonrasında ilgili faktörle ilişkilendirilemeyen maddeler (t2, t8, t16, t20, t40) ile uygulama sırasında 5 ve 6 . sınıf öğrencileri tarafından anlaşılmadığı ifade edilen maddeler $(t 31, t 32)$ uzman görüşü alınarak ölçekten atılmıştır. Sonrasında $.45^{\prime}$ in altında bulunan ve yük değerleri arasındaki farka göre faktörler arasında binişiklik oluşturan maddeler (t22, t24, t27) ölçekten atılmıştır. Yapılan son döndürülmüş faktör analizi sonrasında 41 maddeden 18 madde atılarak 23 maddeden oluşan, öz değeri 1 'in üzerinde olan ve toplam varyansın $\% 58,96$ 'sını oluşturan 3 faktörlü bir yapı tespit edilmiştir. Bu yapı, Tablo 1'de gösterilmiştir:

Tablo 1.

Açımlayıcı Faktör Analizi Sonuçları

\begin{tabular}{cccccc}
\hline $\begin{array}{c}\text { Ölçek Taslak } \\
\text { Formu } \\
\text { Madde No. }\end{array}$ & $\begin{array}{c}\text { Ölçek } \\
\text { Madde } \\
\text { No. }\end{array}$ & Faktör 1 & Faktör 2 & Faktör 3 & $\begin{array}{c}\text { Düzeltilmiş } \\
\text { Madde } \\
\text { Toplam } \\
\text { Korelasyonu }\end{array}$ \\
\hline t17 & $\mathrm{m} 13$ & Sevgi ve Ilgi & \\
t19 & $\mathrm{m} 15$ &, 800 & &, 787 \\
t6 & $\mathrm{m} 5$ &, 800 & &, 666 \\
& &, 730 & &, 682
\end{tabular}




\begin{tabular}{|c|c|c|c|c|c|}
\hline $\mathrm{t} 21$ & $\mathrm{~m} 16$ & 702 & & & 700, \\
\hline t29 & $\mathrm{m} 20$ & 668, & & & 611 \\
\hline $\mathrm{t} 10$ & $\mathrm{~m} 8$ & 647, & & & 736, \\
\hline $\mathrm{t} 3$ & $\mathrm{~m} 2$ & 646, & & & 726, \\
\hline $\mathrm{t} 4$ & $\mathrm{~m} 3$ & 645, & & & 689, \\
\hline $\mathrm{t} 25$ & $\mathrm{~m} 17$ & 629 & & & 761 \\
\hline $\mathrm{t} 1$ & $\mathrm{~m} 1$ & 627 & & & ,726 \\
\hline t9 & $\mathrm{m} 7$ & 623 & & & 740 \\
\hline t41 & $\mathrm{m} 23$ & 597, & & & 673 \\
\hline $\mathrm{t} 12$ & $\mathrm{~m} 10$ & 576, & & & 642 \\
\hline & \multicolumn{5}{|c|}{ Gereklilik } \\
\hline t11 & $\mathrm{m} 9$ & & ,744 & & 454 \\
\hline $\mathrm{t} 7$ & $\mathrm{~m} 6$ & & 715 & & 631 \\
\hline $\mathrm{t} 14$ & $\mathrm{~m} 12$ & & 647, & & ,550 \\
\hline $\mathrm{t} 5$ & $\mathrm{~m} 4$ & & 603 & & 570, \\
\hline \multirow[t]{2}{*}{$\mathrm{t} 18$} & $\mathrm{~m} 14$ & & ,598 & & ,656 \\
\hline & & & \multicolumn{3}{|c|}{ Kaygı } \\
\hline t13 & $\mathrm{m} 11$ & & & ,706 & ,521 \\
\hline $\mathrm{t} 26$ & $\mathrm{~m} 18$ & & & 681 & ,587 \\
\hline $\mathrm{t} 30$ & $\mathrm{~m} 21$ & & & 660 & 558, \\
\hline t28 & $\mathrm{m} 19$ & & & 649 & 652 \\
\hline t34 & $\mathrm{m} 22$ & & & 642 & ,546 \\
\hline
\end{tabular}

Tablo 1 incelendiğinde 23 maddeden oluşan ölçeğin faktör yük değerlerinin ,800 ile ,576 arasında değiştiği görülmektedir. Bu faktörlere ait varyans yüzdeleri ile toplam varyans yüzdeleri şu şekildedir:

Tablo 2.

Faktörlerin Varyans Yüzdeleri ve Toplam Varyansları

\begin{tabular}{lcc}
\hline Faktörler & Varyans Yüzdesi (\%) & Toplam Varyans (\%) \\
\hline Faktör 1: Sevgi ve ilgi & 28,935 & 28,935 \\
Faktör 2: Gereklilik & 15,834 & 44,769 \\
Faktör 3: Kaygı & 14,194 & 58,963 \\
\hline
\end{tabular}

Tablo 2 incelendiğinde ölçeğin tümü, toplam varyansın 58,96'sını karşılamaktadır. Büyüköztürk (2017, s. 135), açıklanan varyansın yüksek olmasının ilgili kavram ya da yapının o denli iyi ölçüldüğünün bir göstergesi olarak yorumlamaktadır. Bununla birlikte ölçeğe ait faktörlerin de varyans yüzdeleri tespit edilmiştir.

TDTÖ'de yer alan "Sevgi ve İlgi" boyutunun 13 maddeden oluştuğu belirlenmiş olup bu maddelerin Varimax dik döndürme yöntemiyle döndürülmüş faktör yük değerlerinin ,800 ile, 576 arasında değiştiği gözlenmiştir. Faktöre ait varyans oranı ise \%28,935 olarak bulunmuştur.

TDTÖ'de yer alan "Gereklilik" boyutunun 5 maddeden oluştuğu belirlenmiş olup bu maddelerin Varimax dik döndürme yöntemiyle döndürülmüş faktör yük değerlerinin ,744 ile ,598 arasında değiştiği gözlenmiştir. Faktöre ait varyans oranı ise $\% 15,834$ olarak bulunmuştur.

TDTÖ'de yer alan "Kaygı" boyutunun 5 maddeden oluştuğu belirlenmiş olup bu maddelerin Varimax dik döndürme yöntemiyle döndürülmüş faktör yük değerlerinin ,706 ile ,642 arasında değiştiği gözlenmiştir. Faktöre ait varyans oranı ise \%14,194 olarak bulunmuştur. Faktörlere ait Pearson Korelasyon Katsayıları şu şekildedir: 
Tablo 3.

Faktörlere Ait Pearson Korelasyon Katsayıları

\begin{tabular}{lcccc}
\hline & Faktör 1 & Faktör 2 & Faktör 3 & Toplam \\
\hline Faktör 1 & 1 &, $688^{* *}$ &, $680^{* *}$ &, $964^{* *}$ \\
Faktör 2 &, $688^{* *}$ & 1 &, $603^{* *}$ &, $808^{* *}$ \\
Faktör 3 &, $680^{* *}$ &, $603^{* *}$ & 1 &, $818^{* *}$ \\
Toplam &, $964^{* *}$ &, $808^{* *}$ &, $818^{* *}$ & 1 \\
\hline
\end{tabular}

** $p<0.01$

Tablo 3'te ölçeğe ait faktörlerin birbiriyle ve toplam puanıyla ilişkisi incelenerek yapı geçerliğine ek kanıt olarak Pearson Korelasyon Katsayıları $(r)$ hesaplanmıştır. "Korelasyon katsayısının, mutlak değeri 0.70-1.00 arasında yüksek; 0.69-0.30 arasında orta; 0.29-0.00 arasında olması ise, düşük düzeyde bir ilişki olarak tanımlanabilir" (Büyüköztürk, 2017, s. 32). TDTÖ'de sırasıyla birinci faktör $(r=.96)$, üçüncü faktör ( $r=.82)$ ve ikinci faktör ( $r=.81)$ olmak üzere her faktörün ölçeğin geneline ait korelasyon değeriyle yüksek düzeyde pozitif bir ilişkiye sahip olduğu tespit edilmiştir.

\section{Doğrulayıcı Faktör Analiziyle ilgili Bulgular}

Açımlayıcı faktör analizi sonrası 23 maddeden oluşan ve üç faktörlü bir yapıya sahip olan ölçeğin farklı bir çalışma grubuna uygulandı̆̆ında faktör özellikleri ve madde sayısının korunup korunmadığını sınamak amacıyla doğrulayıcı faktör analizi yapılmıştır. 342 öğrencinin verileri SPSS programına aktarılmış ve aynı değişkeni yeniden kodlama seçeneği kullanılarak dönüştürülmüştür. Bu veriler, LISREL paket programına aktarılarak uyum indeksleri hesaplanmıştır:

Tablo 4.

TDTÖ'nün Uyum Indeksleri

\begin{tabular}{cccccccc}
\hline Model & $\chi^{2} / \mathbf{s d}$ & RMSEA & CFI & NNFI & NFI & GFI & SRMR \\
\hline & $497,88 / 225=2,21$ & .06 & .98 & .98 & .97 & .89 & .05 \\
\hline
\end{tabular}

Yapılan analizde uyum indeksleri incelenmiş ve aynı faktörde bulunan 1 ve 2 . maddelerin, 3 ve 8. maddelerin hata varyansları birbiri ile ilişkilendirilmiştir. Doğrulayıcı faktör analizinde yapının uygunluğu $\chi^{2} / \mathrm{sd}$, RMSEA, CFI, NNFI, NFI, GFI ve SRMR model uyum indeksleri ile test edilmiştir. Incelenen uyum indeksleri; $\chi^{2}=497,88 ; s d=225 ; \chi^{2} / s d=2,21 ; R M S E A=0,060 ; C F I=0,98 ; N N F I=0,98$; $\mathrm{NFI}=0,97 ; \mathrm{GFI}=0,89 ; \mathrm{SRMR}=0,055$ olarak hesaplanmıştır. "Ki-karenin serbestlik derecesine oranının $\left(\chi^{2} / s d\right)$ 3'ten küçük olması, ki-karenin anlamlı dahi olsa modelin genel uyumunun kabul edilebilir olduğu sonucunu vermektedir" (Meydan ve Şeşen, 2011, s. 32). Browne ve Cudeck (1992, s. 239), 0.05 veya daha düşük bir RMSEA değerinin modelin serbestlik derecesine göre yakın bir uyumunu göstereceğini; 0.08 veya daha düşük bir değerin ise makul yakınlık hatalarını temsil edebileceğini ifade etmektedir. Kline (2011, s. 208), CFI değerinin .95 ve üzerinde olması; SRMR değerinin ise .08 ve altında olmasının iyi uyuma işaret ettiğini belirtmektedir. GFI uyum indeksi incelendiğinde, Cole (1987, s. 586) bu değerin 0.8 ve üzerinde olmasının genellikle iyi bir uyum olduğunu ifade ederken, Anderson ve Gerbing (1984, s. 166) ise bu değerin 0.85 'in üzerinde olmasının kabul edilebilir olduğunu belirtirler. Maddelerin birlikte bulundukları faktördeki t değerlerinin 11,67 ile 17,24 arasında değiştiği ve ölçekteki maddelerin modele anlamlı olarak katkı sağladığı tespit edilmiştir $(p<0.05)$. Şekil 1 'de TDTÖ’nün birinci düzey doğrulayıcı faktör analizi diyagramına yer verilmiştir: 


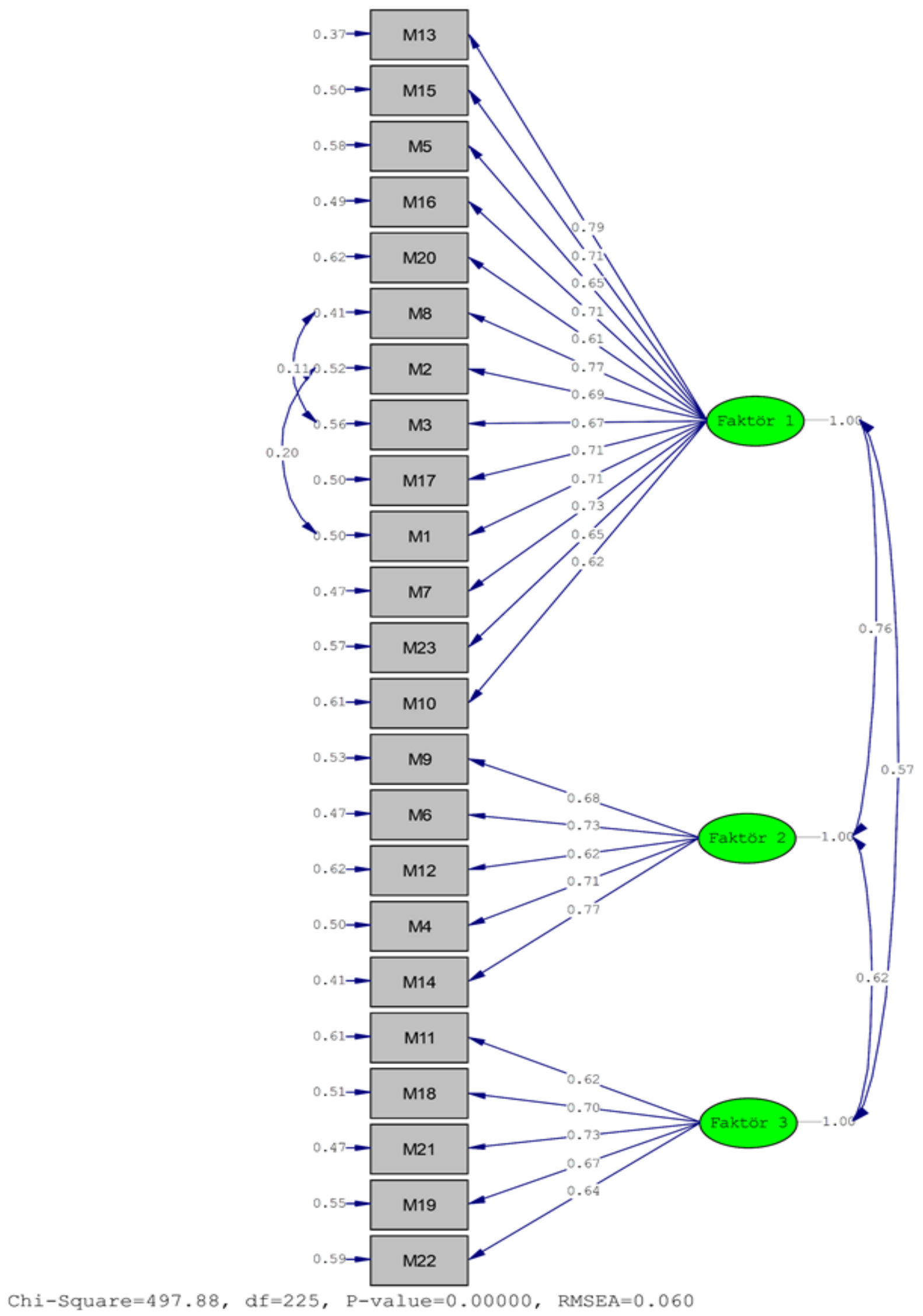

Şekil 1. Ölçeğin Doğrulayıcı Faktör Analizi Diyagramı 


\section{Güvenirlikle İlgili Bulgular}

TDTÖ’nün Cronbach Alpha iç tutarlılık katsayısı 0.933 olarak hesaplanmıştır. Ölçeğin alt boyutlarına ait güvenirlik katsayıları ise Tablo 5 'te gösterilmiştir:

Tablo 5.

Faktörlerin Güvenirlik Hesaplamaları

\begin{tabular}{lc}
\hline & $\begin{array}{c}\text { Cronbach Alpha İç } \\
\text { Tutarlılık Katsayısı }\end{array}$ \\
\hline Faktör 1: Sevgi ve İlgi & $\alpha=0.925$ \\
Faktör 2: Gereklilik & $\alpha=0.817$ \\
Faktör 3: Kaygı & $\alpha=0.806$ \\
\hline
\end{tabular}

TDTÖ’nün iç tutarlılık katsayıları; “Sevgi ve ilıi” boyutu için 0.925, "Gereklilik” boyutu için 0.817 ve "Kaygı" boyutu için 0.806 'dır. Bu hesaplamalar sonucunda ölçeği oluşturan maddelerin birbiriyle tutarlı olduğu ve ölçmek istediği tutumu yansıttığı söylenebilir.

\section{Sonuç ve Öneriler}

Bu çalışmada ortaokul öğrencilerinin Türkçe dil bilgisine yönelik tutumlarını ölçmek amacıyla geçerli ve güvenilir bir ölçme aracı geliştirmek amaçlanmıştır. Literatürde Türkçe eğitimi alanında geliştirilmiş tutum ölçekleri incelenmiştir (Acat, 2000; Gömleksiz, 2003; MEB, 2006; Kuşdemir Kayıran, 2007; Özbay ve Uyar, 2009; İşeri ve Ünal, 2010; Topçuoğlu Ünal ve Köse, 2014; Çerçi ve Derman, 2016; Er ve Topçuoğlu Ünal, 2016; Özkaya ve Coşkun, 2018). Geliştirilen ölçekler içerisinde ortaokul öğrencilerinin Türkçe dil bilgisine yönelik tutumlarını ölçecek nitelikte iki çalışmayla karşılaşılmıştır (Er ve Topçuoğlu Ünal, 2016; Özkaya ve Coşkun, 2018). Öncelikle dil bilgisine yönelik kuramsal bilgilerden ve yaklaşımlardan hareketle 48 maddeli bir havuz oluşturulmuş ve sonrasında bu maddelerde yer alan ifadelerle ilgili uzman görüşü alınarak 41 maddeli form uygulamaya hazır hâle getirilmiştir. Bu formda dil bilgisinin konuları, etkinlikleri ve sorularına yönelik ifadelere yer verilmiştir.

Öğrenciler tarafından TDTÖ'nün maddelerine verilen yanıtlar SPSS paket programına aktarılarak açımlayıcı faktör analizi (AFA) yapılmıştır. Sosyal bilimlerde yaygın olarak kullanılan bu analiz, bir dizi yanıtı etkileyen yapıların doğasını keşfetmeye çalışır (Costello \& Osborn, 2005; DeCoster, 1998). 574 ortaokul öğrencisine uygulanan çalışmada KMO değerinin .969; Bartlett's testinin ise anlamlı olduğu tespit edilmiştir $\left(X^{2}=12839,806, d f=820, p=.000\right)$. Bu değerler, açımlayıcı faktör analizinin yapılabilme koşulunu sağladığını göstermiştir. Analiz sonucunda daha az sayıda faktöre ulaşabilmek amaçlanmış ve çizgi grafiği incelendiğinde üç faktörlü bir yapının olabileceği görülmüştür. Faktörlerin açıkladığı varyans oranı, yük değerleri ve bu değerler arasındaki farklara bakılarak $15^{\prime} \mathrm{i}$ olumlu, 8'i olumsuz olmak üzere 23 maddeden oluşan 5'li likert tipinde bir ölçek elde edilmiştir. Ölçeğin maddelerinde yer alan içeriklere bağı olarak ilk boyut "Sevgi ve illgi", ikinci boyut "Gereklilik" ve üçüncü boyut "Kaygı" olarak adlandırılmışır. Bu işlemler sonucunda ilgili yapının toplam varyansın $\% 58,96$ 'sını açıkladığı belirlenmiştir.

Açımlayıcı faktör analizi sonrasında bir dizi gözlemlenen değişkenlere ait örtük yapılar arasındaki ilişkiyi doğrulamak (Suhr, 2006, s. 1) amacıyla farklı bir grup üzerinde ölçeğin doğrulayıcı faktör analizi (DFA) yapılmıştır. Bu analizde ortaya çıkan yapının geçerliği sınanmış ve farklı çalışma grubuna uygulanan ölçeğin üç faktörlü bir yapıya sahip olduğu doğrulanmıştır. SPSS'deki veriler LISREL'e aktarılarak TDTÖ'ye ait uyum indeksleri; $\chi^{2}=497,88, \mathrm{sd}=225, \chi^{2} / \mathrm{sd}=2,21, \mathrm{RMSEA}=0,060$; $\mathrm{CFI}=0,98 ; \mathrm{NNFI}=0.98 ; \mathrm{NFI}=0,97 ; \mathrm{GFI}=0,89 ; \mathrm{SRMR}=0,055$ olarak tespit edilmiştir. Bu değerler, ölçeğin iyi uyum değerlerine sahip olduğunu göstermektedir.

TDTÖ’nün Cronbach Alpha iç tutarlılık katsayısı hesaplanarak güvenirlik analizi gerçekleştirilmiş ve ölçeğin tümüne ait iç tutarlılık katsayısı 0.933 olarak bulunmuştur. Ölçeğin alt boyutlarının iç tutarlıık katsayıları incelendiğinde "Sevgi ve ilgi" boyutu için 0.925; "Gereklilik" boyutu için 0.817; "Kaygı" boyutu için 0.806 olduğu tespit edilmiştir.

Sonuç olarak Türkçe Dil Bilgisi Tutum Ölçeği, 23 maddeden oluşmakta; öğrencilerin maddelere 
yönelik işaretlemeleri için "Tamamen Katılıyorum", "Katılıyorum", "Kararsızım", "Katılmıyorum" ve "Kesinlikle Katılmıyorum" şeklinde seçeneklere yer verilmektedir. 5'li likert tipinde hazırlanan bu ölçekte olumsuz maddelerde yapılan işaretlemelerin puanları ters çevrilerek toplam puanlar elde edilmiştir. Öğrencilerin maddelere verdikleri yanıtlar analiz edildiğinde ölçme aracından alınan en düşük puan 38, en yüksek puan ise 114 olarak hesaplanmıştır. TDTÖ'de yer alan faktöre ait $t$ değerlerinin 11,67 ile 17,24 arasında değiştiği ve ölçekteki maddelerin modele anlamlı olarak katkı sağladığı belirlenmiştir $(p<0.05)$. Ölçeğe ait verilerin sadece Hatay il merkezindeki ortaokul öğrencilerinden toplanmış olması, bu çalışmanın sınırlılı̆ıdır. Farklı illerde ve kırsal bölgelerde gerçekleştirilecek verilerin incelenmesiyle bu sınırlıık ortadan kaldırılabilir.

Bu çalışmadan elde edilen bulgular, TDTÖ’nün ortaokul öğrencilerinin Türkçe dil bilgisine yönelik tutumlarını ölçmede geçerli ve güvenilir bir ölçme aracı olduğunu göstermektedir. Türkçe derslerinde yapılacak dil bilgisi öğretimi çalışmaları öncesinde ortaokul öğrencilerinin dil bilgisine yönelik tutumları belirlenerek öğrencilere uygun etkinlikler tasarlanabilir ve öğrencilerin akademik başarılarıyla ilgili bir karşılaştırmaya gidilebilir.

\section{Araştırma ve Yayın Etiği}

Bu çalışmada "Yükseköğretim Kurumları Bilimsel Araştırma ve Yayın Etiği Yönergesi" kapsamında uyulması belirtilen tüm kurallara uyulmuştur. Yönergenin ikinci bölümü olan "Bilimsel Araştırma ve Yayın Etiğine Aykırı Eylemler" başlığı altında belirtilen eylemlerden hiçbiri gerçekleştirilmemiştir.

\section{Yazarların Katkı Oranı}

Çalışmaya birinci yazar \%60, ikinci yazar \%40 oranında katkı sağlamıştır.

\section{Çıkar Çatışması}

Bu araştırmada çıkar çatışması teşkil edebilecek herhangi bir durum ya da ilişki yoktur.

\section{Kaynaklar}

Acat, M. B. (2000). Dilin işlevselliği yaklaşımına göre hazırlanmış Türkçe öğretimi programının temel dil becerilerinin kazanılmasına etkisi. (Doktora Tezi). Yüksek Öğretim Kurulu Ulusal Tez Merkezi. (Tez No. 98550).

Anderson, J. C., \& Gerbing, D. W. (1984). The effect of sampling error on convergence, improper solutions, and goodness-of-fit indices for maximum likelihood confirmatory factor analysis. Psychometrika, 49(2), 155-173.

Aytaş, G. ve Çeçen, M. A. (2010). Ana dili eğitiminde dil bilgisi öğretiminin yeri ve önemi. Türklük Bilimi Araştırmaları, (27), 77-89.

Büyüköztürk, Ş. (2017). Sosyal bilimler için veri analizi el kitabı. Ankara: Pegem Akademi Yayıncılık.

Browne, M. W., \& Cudeck, R. (1992). Alternative ways of assessing model fit. Sociological Methods \& Research, 21(2), 230-258.

Can, A. (2017). SPSS ile bilimsel araştırma sürecinde nicel veri analizi. Ankara: Pegem Akademi Yayıncilık.

Cole, D. A. (1987). Utility of confirmatory factor analysis in test validation research. Journal of Consulting and Clinical Psychology, 55(4), 584-594.

Costello, A. B., \& Osborne, J. W. (2005). Best practices in exploratory factor analysis: Four recommendations for getting the most from your analysis. Practical Assessment, Research, and Evaluation, 10(7), 1-9.

Çerçi, A. ve Derman, S. (2016). Türkçe etkinliklerine yönelik tutum ölçeği geliştirilmesi: Geçerlilik ve güvenirlik çalışması. Ana Dili Eğitimi Dergisi, 4(4), 461-473.

DeCoster, J. (1998). Overview of factor analysis. Erişim Adresi: http://www.stat-help.com/notes.html

Dolunay, S. K. (2010). Dil bilgisi öğretiminin amacı ve önemi. Türklük Bilimi Araştırmaları, (27), 275-284. 
Er, K. ve Topçuoğlu Ünal, F. (2016). Ortaokul öğrencilerine yönelik dil bilgisi tutum ölçeği geliştirilmesi: Geçerlilik ve güvenirlik çalışması. Mehmet Akif Ersoy Üniversitesi Eğitim Fakültesi Dergisi, 40, 343-356.

Erdem, i. ve Çelik, M. (2011). Dil bilgisi öğretim yöntemi üzerine değerlendirmeler. Turkish Studies. 6(1), 1057-1069.

Field, A. (2009). Discopering statistics using SPSS. California: Sage Publications.

Göğüş, B. (1978). Orta dereceli okullarda Türkçe ve yazın eğitimi. Ankara: Gül Yayınevi.

Gömleksiz, M. N. (2003). İngilizce duyuşsal alana ilişkin bir tutum ölçeğinin geçerlik ve güvenirliği. Fırat Üniversitesi Sosyal Bilimler Dergisi, 13(1), 215-226.

Güneş, F. (2013). Dil bilgisi öğretiminde yeni yaklaşımlar. Dil ve Edebiyat Eğitimi Dergisi, 2(7), 71-92.

Güven, A. Z. (2013). Dil bilgisi konularının öğretim sorunları. Dil ve Edebiyat Eğitimi Dergisi, 2(6), 1-10.

Hamzadayı, E. ve Şentürk. R. (2020). Dilbilgisi öğretimi: Hangi öğretim yolu?. A. Pehlivan ve i. S. Aydın (Ed.), Dil Bilgisi Öğretimi kitabı içinde (s. 75-100). Ankara: Pegem Akademi Yayıncılık.

İşcan, A., ve Kolukısa, H. (2005). İlköğretim ikinci kademe dil bilgisi öğretiminin durumu, sorunları ve çözüm önerileri. Atatürk Üniversitesi Sosyal Bilimler Enstitüsü Dergisi, 5(1), 299-308.

İşeri, K. ve Ünal, E. (2010). Yazma eğilimi ölçeği'nin Türkçeye uyarlanması. Eğitim ve Bilim, 35(155), $104-$ 117.

Jöroskog, K. G., \& Sörbom, D. (1993). LISREL 8: structural equation modeling with the SIMPLIS command language. Lincolnwood: Scientific Software International, Inc.

Kalaycı, Ş. (2018). SPSS uygulamalı çok değişkenli istatistik teknikleri. Ş. Kalaycı (Ed.). Ankara: Dinamik Akademi Yayıncılık.

Katz, D. (1960). The functional approach to the study of attitudes. Public Opinion Quarterly, 24(2), 163204.

Kline, R. B. (2011). Principles and practice of structural equation modeling. New York: The Guilford Press.

Kurudayıoğlu, M. (2014). Dünyada ve Türkiye'de dil bilgisi öğretiminin temel problemleri. M. Özbay (Ed.), Türkçe Eğitimi Açısından Dil Bilgisi Öğretimi kitabı içinde (s. 47-69) Ankara: Pegem Akademi Yayıncılık.

Kuşdemir Kayıran, B. (2007). Çoklu zekâ kuramı destekli kubaşık öğrenme yönteminin Türkçe dersine ilişkin tutum ve okuduğunu anlamaya yönelik akademik başarı üzerindeki etkisi. (Yüksek Lisans Tezi). Yüksek Öğretim Kurulu Ulusal Tez Merkezi. (Tez No. 220591).

Larsen-Freeman, D. (1997). Grammar and its teaching: Challenging the myths. ERIC Clearinghouse on Languages and Linguistics Washington DC, 1-7.

Leech, N. L., Barrett, K. C., \& Morgan, G. A. (2005). SPSS for intermediate statistics: Use and interpretation. New Jersey: Lawrence Erlbaum Associates Inc., Publishers.

MEB. (2006). Illköğretim Türkçe dersi $(6,7,8$. sınıflar) öğretim programı. Ankara: MEB Talim ve Terbiye Kurulu Başkanlı̆̆ı.

Meydan, C. H., \& Şeşen, H. (2011). Yapısal eşitlik modellemesi AMOS uygulamaları. Ankara: Detay Yayıncilık.

Onan, B. (2017). Dil bilgisi öğretiminde sentezci yaklaşım. Uluslararası Türkçe Edebiyat Kültür Eğitim (TEKE) Dergisi, 6(4), 2627-2638.

Özbay, M. ve Uyar, Y. (2009). Illköğretim ikinci kademe öğrencileri için okumaya yönelik tutum ölçeğinin geliştirilmesi: Geçerlilik ve güvenirlik çalışması. Journal of New World Sciences Academy Education Sciences, 4(2), 632-651.

Özkaya, P. G. ve Coşkun, M. V. (2018). Dil bilgisine yönelik tutum ölçeği'nin geliştirilmesi: Geçerlik ve güvenirlik çalışması. Ana Dili Eğitimi Dergisi, 6(3), 636-651.

Pallant, J. (2007). SPSS survival manual: A step by step guide to data analysis using SPSS for Windows. New York: McGraw-Hill Open University Press.

Salman, B., \& Aydın, İ. S. (2018). Yapılandırmacı yaklaşıma göre dil bilgisi öğretimine yönelik öğretmen görüşleri. Turkish Studies, 13(27), 1265-1284.

Suhr, D. D. (2006). Exploratory or confirmatory factor analysis? Statistics and data analysis, SUGI 31, San Francisco, CA. Erişim Adresi: http://www2.sas.com/proceedings/sugi31/200-31.pdf 
Tabachnick, B. G., \& Fidell, L. S. (2013). Using multivariate statistics. Boston: Pearson.

Tavşancıl, E. (2006). Tutumların ölçülmesi ve SPSS ile veri analizi. Ankara: Nobel Akademi Yayıncılık.

Tezbaşaran, A. (2008). Likert tipi ölçek hazırlama kılavuzu. Ankara: Türk Psikologlar Derneği.

Tompkins, G. E. (1998). Language arts content and teaching strategies. New Jersey: California State University Prentice-Hall Inc.

Topçuoğlu Ünal, F. ve Köse, M. (2014). Türkçe dersine yönelik tutum ölçeği geliştirilmesi: Bir geçerlilik ve güvenirlik çalışması. Journal of Faculty of Education, 3(2), 141-159.

Zhang, J. (2009). Necessity of grammar teaching. International Education Studies, 2(2), 184-187.

\section{Introduction}

\section{Extended Abstract}

Human beings express their feelings and thoughts through language to understand each other. Language, which was first developed for reconciliation, is characterized by its own rules. Grammar is a branch of science that seeks a thorough study of such rules. Mastery of the grammar of a language is pivotal for the ability to correctly use comprehension and expression skills in that language. Only a grammar teaching designed considering the curriculum can present activities to allow individuals to improve their language skills. The main purpose of grammar teaching, an auxiliary and complementary area for the development of language skills, is to ensure that individuals learn their native language in a perfect way (Dolunay, 2010; Aytaş and Çeçen, 2010). Understanding of attitudes of learners towards grammar would offer much help studies in this field as well as educational practices. Because attitudes refer to one's tendency to consider some symbols, objects or views in their world in a positive or negative way (Katz, 1960, p. 168). Attitudes are not innate but learned through experiences; further, they are not temporary but persistent for a certain period of time. A positive or negative attitude is developed through comparisons, and two types of attitudes as personal and social attitudes can be identified (Tavşancıl, 2006, pp. 71-72). In this regard, attitudes can shape the behaviors of individuals. According to Özkaya and Coşkun (2018, p. 638), understanding of students' attitudes towards grammar will allow for eliminating the shortcomings in the education and training practice and designing curricula aimed at attracting students' attention and enhancing their success. Moreover, students' attitudes towards grammar may emerge as a research subject to reveal the effects of the practices designed by teachers on attitudes. Accordingly, this attitudes scales, intended to determine the attitudes of secondary school students towards Turkish grammar, feature three dimensions as "Liking and Interest", "Necessity" and "Anxiety."

\section{Method}

This study is a research intended at measuring the validity and reliability of the Attitudes Scale towards Turkish Grammar (ASTG). The study group for the exploratory and confirmatory factor analysis consists of the randomly-selected secondary-level students who study at $5^{\text {th }}, 6^{\text {th }}, 7^{\text {th }}$, and $8^{\text {th }}$ grades in the spring semester of the 2018-2019 academic year in state schools in the city center of Hatay, Turkey.

The draft form designed in Likert type with 41 items for the exploratory factor analysis was administered to 574 students and the students' answers were calculated from the sum of the grades. The data collected for the factor analysis were analyzed based on the skewness $(-, 523)$ and kurtosis (,538) values; the values met the normality assumptions. The score conversions of the negative items among the answers given by 342 students to 23 items in the confirmatory factor analysis were performed using the option of SPSS to recode into the same variables. The converted data were fed into the LISREL software and analyzed. The Cronbach's Alpha internal consistency coefficient was calculated to test the reliability of the scale, which was finalized after the exploratory and confirmatory factor analyzes.

\section{Result and Discussion}

The purpose of this study is to develop a valid and reliable measurement tool to measure attitudes of secondary school students towards Turkish grammar. To that end, first, a 48-item pool was created based on theoretical knowledge and approaches to grammar, and then a 41-item form was 
finalized based on expert opinion on the items in the form. This form includes statements on grammarrelated subjects, activities and questions.

A exploratory factor analysis (EFA) was performed on the items of the ASTG. This analysis, carried out with 574 secondary school students, found the KMO value as .969 and the Bartlett's test as significant $\left(X^{2}=12839,806, d f=820, p=.000\right)$. These values indicated that the condition to perform exploratory factor analysis was met. The purpose was to yield fewer factors and a three-factor structure was revealed as seen on the line graph too. A 5-point Likert-type scale with 23 items, 15 of which were positive and 8 negative, was developed considering the variance rate explained by the factors, the load values and the differences between these values. As for the content of the scale, the first dimension is named as "Liking and Interest"; the second dimension is "Necessity" and the third dimension is "Anxiety." The final structure explains $58.96 \%$ of the total variance.

The confirmatory factor analysis tested the validity of the resulting structure and confirmed that the scale, administered to another study group, had a three-factor structure. The data on SPSS were fed into LISREL; the fit indices of the ASTG were found as follows: $\chi^{2}=497,88, s d=225, \chi^{2} / s d=2,21$, $\mathrm{RMSEA}=0,060 ; \mathrm{CFI}=0,98 ; \mathrm{NFI}=0.97 ; \mathrm{NNFI}=0,98 ; \mathrm{GFI}=0,89 ; \mathrm{SRMR}=0,055$. This implies that the scale yields good fit indices.

The Cronbach's Alpha internal consistency coefficient of the ASTG was calculated for the conduct of reliability analysis, and the internal consistency of the whole scale was found as 0.933 . The internal consistency coefficients of the sub-dimensions of the scale were calculated and the results are as follows: 0.925 for the dimension of "Liking and Interest"; 0.817 for the dimension of "Necessity"; 0.806 for the dimension of "Anxiety."

As a result, the Attitudes Scale towards Turkish Grammar has 23 items and is rated on the 5point Likert-type with the options ranging from "I strongly agree", "I agree", "I neither agree nor disagree", "I disagree" and "I strongly disagree." Moreover, t-values of the factors in the ASTG varied between 11,67 and 17,24; the items in the scale contributed significantly to the model $(p<0.05)$. The findings of this study ascertained that the ASTG is a valid and reliable measurement tool to measure the attitudes of secondary school students towards Turkish grammar. Gaining an understanding of the attitudes of secondary school students towards grammar before grammar teaching in Turkish language courses would allow for designing more appropriate activities for students and comparing their academic achievements. 
Ek-1

\begin{tabular}{|c|c|c|c|c|c|c|}
\hline & TÜRKÇE DiL BILGGISI TUTUM ÖLÇEĞi & & & & & \\
\hline $\begin{array}{l}\text { Sevg } \\
\text { Bu ö } \\
\text { okuc } \\
\text { belir } \\
\text { "Kes } \\
\text { ceva } \\
\text { işare } \\
\text { dilec }\end{array}$ & $\begin{array}{l}\text { ili Öğrenciler, } \\
\text { çek, sizlerin dil bilgisi ile ilgili görüşlerinizi almak amacı ile hazırlar } \\
\text { uktan sonra sağ tarafta verilen beş seçenekten birini işaretleyer } \\
\text { tiniz. Seçenekler "Tamamen Katılıyorum.", "Katılıyorum.", "Ka } \\
\text { inlikle Katılmıyorum." şeklinde verilmiştir. Lütfen işaretsiz ifa } \\
\text { plar bilimsel araştırmada kullanılacaktır. Duygu ve düşüncelerir } \\
\text { tlemeniz araştırmanın güvenirliği için önemlidir. Katılım g } \\
\text { iğinizde çekilebilirsiniz. Araştırmaya gösterdiğiniz ilgi için teşekki }\end{array}$ & $\begin{array}{l}\text { er bi } \\
\text { yere } \\
\text { ", "K } \\
\text { kmay } \\
\text { i ifad } \\
\text { esa }\end{array}$ & $\begin{array}{l}\text { r cüm } \\
X \text { işa } \\
\text { atılm } \\
\text { ınız. } \\
\text { de ed } \\
\text { asına }\end{array}$ & $\begin{array}{l}\text { nleyi } \\
\text { reti } \\
\text { Iyor } \\
\text { Ver } \\
\text { len } \\
\text { ba }\end{array}$ & $\begin{array}{l}\text { dikk } \\
\text { koyar } \\
\text { um." } \\
\text { eceğ } \\
\text { seçer } \\
\text { ğlı o }\end{array}$ & \\
\hline Adı- & Soyadı: & & Seç & enek & kler & \\
\hline $\begin{array}{l}\text { Oku } \\
\text { Sinıf } \\
\text { Cins }\end{array}$ & yetiniz: ( ) Kız ( ) Erkek & 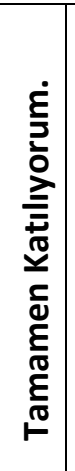 & 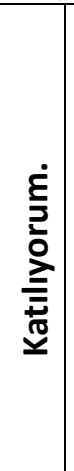 & 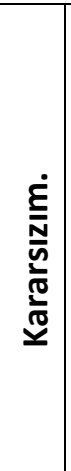 & 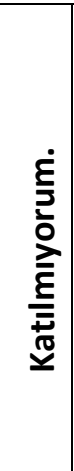 & 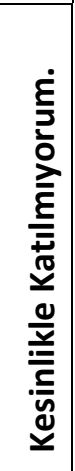 \\
\hline 1. & Dil bilgisi konularını öğrenmeyi seviyorum. & & & & & \\
\hline 2. & Dil bilgisi konularını öğrenirken eğlenirim. & & & & & \\
\hline 3. & Dil bilgisi etkinliklerine katılmayı heyecanla beklerim. & & & & & \\
\hline 4. & Dil bilgisi etkinliklerine mecbur olduğum için katılıyorum.* & & & & & \\
\hline 5. & Dil bilgisi öğretiminin her gün yapılmasını isterim. & & & & & \\
\hline 6. & Dil bilgisinin adını bile duymak beni rahatsız eder.* & & & & & \\
\hline 7. & Dil bilgisi öğrenmeye merakım var. & & & & & \\
\hline 8. & Dil bilgisi etkinliklerine katılmayı çok isterim. & & & & & \\
\hline 9. & Dil bilgisi öğrenmenin zaman kaybı olduğunu düşünüyorum. ${ }^{*}$ & & & & & \\
\hline 10. & Türkçe dersinde en sevdiğim etkinlikler dil bilgisi etkinlikleridir. & & & & & \\
\hline 11. & $\begin{array}{l}\text { Türkçe dersi sınavlarında dil bilgisi sorularıyla karşılaşmaktan } \\
\text { korkarım.* }\end{array}$ & & & & & \\
\hline 12. & Dil bilgisi öğrenmenin gerekli olduğunu düşünüyorum. & & & & & \\
\hline 13. & Dil bilgisi konularının öğretildiği günü sabırsızlıkla beklerim. & & & & & \\
\hline 14. & Türkçe dersinde dil bilgisi öğrenmek bana göre gereksizdir.* & & & & & \\
\hline 15. & $\begin{array}{l}\text { Mümkün olsa boş derslerimde dil bilgisi etkinliklerine katılmak } \\
\text { isterim. }\end{array}$ & & & & & \\
\hline 16. & Dil bilgisiyle ilgili her şey ilgimi çeker. & & & & & \\
\hline 17. & Dil bilgisi ile ilgili yeni konular öğrenmekten mutlu olurum. & & & & & \\
\hline 18. & Dil bilgisi konuları kafamı karıştııır.* & & & & & \\
\hline 19. & Dil bilgisi konularını kolay bir şekilde öğrenirim. & & & & & \\
\hline 20. & Dil bilgisi konularından dolayı en sevdiğim ders Türkçedir. & & & & & \\
\hline 21. & Dil bilgisi ile ilgili sorularda başarılı olamam.* & & & & & \\
\hline 22. & Dil bilgisi konularını anlayamayacağımı düşünüyorum.* & & & & & \\
\hline 23. & Dil bilgisi konularını öğrenirken zaman su gibi akıyor. & & & & & \\
\hline
\end{tabular}

